\title{
$\mathrm{S}$ \\ Turismo e \\ Revista I UFPR
}

\section{Excursões Interestaduais: uma análise geográfica das operações em fretamento rodoviário eventual}

Interstate Excursions: a geographical analysis of occasional road chartering operations

\section{Mauricio Ragagnin Pimentel ${ }^{1}$}

RESUMO: Baseada em dados operacionais de viagens rodoviárias interestaduais e internacionais na modalidade fretamento eventual entre os anos de 2016 a 2019 da ANTT, esta pesquisa exploratória tem por objetivos: (1) caracterizar a distribuição espacial desses deslocamentos, em sua direção e intensidade; (2) apontar as principais origens e as principais destinações destas mobilidades; (3) avaliar a variação anual dos dados analisados; (4) discutir as implicações dos resultados para compreensão das mobilidades turísticas no Brasil. Recorreu-se à estatística descritiva e à cartografia temática. Também se empregaram análises de agrupamento e procedimentos não-paramétricos. Diferente de outras modalidades de transporte, os fretamentos eventuais têm um mercado pulverizado, com muitos atores regionais. Esse tipo de mobilidade é sensível aos feriados, com maiores fluxos no segundo semestre e queda nos meses de verão. Existe uma correlação moderada da quantidade de passageiros em cada trecho entre os distintos anos, indicando a variação dessa oferta de acordo com a conjuntura. Apesar das variações de posição, alguns destinos chave são recorrentes.

\footnotetext{
1 Doutorado e Mestrado em Geografia pela Universidade Federal do Rio Grande do Sul (UFRGS). Bacharelado em Turismo pela Pontifícia Universidade Católica do Rio Grande do Sul (PUCRS). Professor de Turismo na Universidade Federal de Pelotas (UFPel).

E-mail: mauricioragagnin@gmail.com
} 
O estudo contribui para a compreensão dos fluxos e redes de mobilidades que permitem a apropriação e o uso turístico do território brasileiro. Propõe uma metodologia para interpretar uma base de dados de acesso aberto de abrangência nacional que tem sido negligenciada na literatura científica em Turismo. Ao recorrer ao uso de evidências empíricas, os resultados são adequados para avaliar esforços de políticas públicas para o setor. Ao final, são apontados recortes para estudos futuros explorando a base de dados da ANTT.

Palavras-chave: Fretamento eventual; Distribuição espacial; Mobilidades turísticas; Transporte rodoviário; ANTT.

ABSTRACT: Based on the Brazilian Federal Agency of Land Transportation (ANTT) dataset to interstate and international charter coach trips between the years of 2016 and 2019, the goals of this exploratory research are: (1) to characterize the spatial distribution of such mobilities, assessing its' directions and intensities; (2) to identify these trips main origins and destinations; (3) to assess data yearly variation; (4) to discuss results implications for the understanding of tourism mobilities in Brazil. To fulfill these purposes descriptive statistics and theme cartography were deployed. Cluster analysis and non-parametric techniques were also used. Unlike other transportation modes, charter coach trips in Brazil form a pulverized market with many regional companies. This kind of mobility is sensitive to holidays. Therefore, it has a more intense flow on the second semester, declining on the summer. There is a moderate correlation when comparing each route number of passengers between different years. Which points to the situational sensitivity of this kind of mobility. Despite some changes in ranking position from year to year, some destinations are regularly on the top positions. This study contributes to the understanding of mobilities flows and networks that afford an appropriation and use of the Brazilian territory for tourism. It also proposes a way to analyze an open access dataset with national coverage that has been neglected by tourism academic literature. As they are grounded in empirical evidence the results are appropriate to evaluate efforts undertaken in Brazilian tourism policies. Future studies possibilities using ANTT dataset are outlined.

Keywords: Charter coach bus; Spatial distribution; Tourism mobilities; Land transport; ANTT. 


\section{INTRODUC̣ÃO}

O Brasil recebe $0,5 \%$ do número de chegadas mundiais de turistas (UNWTO, 2019). A distância dos principais polos emissores mundiais contribui para esse quadro (TAVARES; LEITÃO, 2017), prejudicando a competitividade do país frente a destinos com maior conectividade e preços mais atrativos. Existem ainda fatores como a taxa de câmbio em relação aos países vizinhos, a imagem associada à violência e a baixa eficiência da promoção turística. Isso torna o mercado doméstico o principal propulsor do turismo no país.

Apesar de sua importância, obter dados para investigar o turismo doméstico é um desafio. Diferentemente do turismo internacional, não existem controles migratórios que facilitem a coleta estatística. Uma fonte importante para compreensão dessas mobilidades foram as Pesquisas de Demanda Doméstica encomendadas pelo Ministério do Turismo à FIPE (2001 a 2012). No último ano, 2012, havia a estimativa de 60 milhões de turistas, em 200 milhões de deslocamentos. À época, o automóvel particular e o avião eram os principais meios de deslocamento. Já os fretamentos eventuais variavam de $4,7 \%$ a $7 \%$ do total de viagens realizadas.

Outra fonte para compreensão do fluxo de pessoas no Brasil é o Anuário dos Transportes, do Ministério da Infraestrutura (2019). A publicação aponta a média anual de 10,5 milhões de passageiros em fretamento eventual interestadual entre 2009 e 2018. Isso corresponde a 7,8\% dos deslocamentos entre estados, frente aos 82 milhões $(60,6 \%)$ de passageiros do transporte aéreo e aos 43 milhões $(31,7 \%)$ do rodoviário em linhas regulares. Exclui-se aqui o transporte em veículos particulares.

Embora não sejam a modalidade mais frequente, os fretamentos eventuais congregam uma diversidade de mobilidades que tem sido negligenciada e que merece uma atenção maior de estudos acadêmicos. Particularmente, considerando os avanços teóricos do 'Paradigma das Mobilidades' (KUNZ, 2015). Com a emergência de uma sociedade cada vez mais globalizada e conectada, essa perspectiva questiona o papel das estruturas e dos fixos na teoria social. Busca, então, examinar a sociedade a partir dos significados, performances e implicações dos movimentos e suas conexões. Movimentos de pessoas, mercadorias, objetos, tecnologias, fluxos financeiros e informacionais.

Em uma análise geográfica, estudar os fretamentos eventuais permite conhecer padrões de interação espacial, bem como, de apropriação e de articulação de territórios promovida pelo turismo. Além disso, existem aspectos sociológicos e identitários associados a quem realiza esse tipo de deslocamento. Os fretamentos eventuais, popularmente conhecidos como excursões rodoviárias, tiveram papel considerável na democratização do turismo (WALTON, 2011). Solha e Luques (2011, s.p.) afirmam que "os poucos estudos sobre o uso de ônibus turístico não permitem detalhar a dinâmica e as especificidades deste setor".

Este estudo analisa dados operacionais de viagens autorizadas em fretamento eventual, publicamente disponíveis no portal da Agência Nacional de Transportes Terrestres [ANTT]. Essa autarquia federal tem, entre outras, a competência de 
autorizar o "transporte de passageiros por empresa de turismo e sob regime de fretamento quando esse ultrapassa os limites de uma unidade federativa ou sai do país" (BRASIL, 2001). São objetivos deste estudo: (1) caracterizar a distribuição espacial dos deslocamentos em fretamento eventual interestadual e internacional, considerando sua direção e intensidade; (2) apontar as principais origens e as principais destinações desse tipo de mobilidade; (3) avaliar a variação dos dados entre os diferentes anos; (4) discutir as implicações dos resultados para compreensão das mobilidades turísticas no Brasil.

Assim, inicialmente qualificou-se as mobilidades em fretamento eventual e suas particularidades. Em seguida, descreveu-se os procedimentos de tratamento e análise dos dados, para então discutir os resultados.

\section{REVISÃO DE LITERATURA}

A descrição de fluxos de passageiros em suas direções e intensidades, avaliando os padrões de distribuição no território, é tema recorrente em estudos geográficos sobre turismo (BECKEN, 2006; FORER; PEARCE, 1984; PEARCE, 1987). Contudo, a maior parte considera o modal aéreo. Há escassez de estudos que retratem deslocamentos rodoviários, especialmente, por ônibus.

Para Lévy (2001) as mobilidades são uma relação social de grande riqueza. Elas certamente ultrapassam o aspecto descritivo dos fluxos, pois indicam o modo como as sociedades lidam com o problema das distâncias em suas interações. Distâncias que ultrapassam a conhecida dimensão euclidiana - dos quilômetros ou milhas - como a distância-custo e a distância-tempo, em uma pluralidade de métricas e ritmos. Por exemplo, os mil quilômetros em linha reta entre Brasília (DF) e Curitiba $(\mathrm{PR})$ podem ser feitos em duas horas de avião. A linha reta é a mesma que separa Brasília (DF) e Tucumã (PA), cuja viagem mais rápida com recurso a diferentes modais não ocorre em menos de 8 horas. A mesma diferença vale para os preços e tempo de espera dos fretes entre os dois trechos. "Vivemos num mundo que se movimenta em várias velocidades"(LÉVY, 2001, p.6).

O que significa, em termos de relação social, mudar de local? Quais são as mobilidades possíveis desde um determinado espaço? Que locais são acessíveis? Que competências e capitais são requisitados aos sujeitos para servirem-se dessa oferta? Como as possibilidades e escolhas de deslocamento tornam a mobilidade um capital tanto social quanto espacial? Embora sejam questões que ultrapassem o escopo deste texto, elas auxiliam a situar as problemáticas investigadas pelo campo de estudos sobre mobilidades. Como aponta Haesbaert (2011), a reprodução social significa viver em redes, em que as referências espaço-simbólicas são feitas não só pelo enraizamento, mas também pela mobilidade. 
que Raffestin (1980)1 classifica como um "sistema de malhas, nós e redes", ou pelo que Souza (1995)² propõe como "território descontínuo ou territóriorede" (FRATUCCI, 2000, p.126).

Sublinhando a dimensão espacial, onde se concretiza a atuação dos agentes sociais, Fratucci, Moraes e Allis (2015) propõem o estudo desses territórios-rede como agenda de pesquisa para compreensão do turismo e de seus processos. Tendo em vista tal proposta, este texto busca compreender quais são os territórios articulados nessas redes de mobilidades dos fretamentos eventuais.

Quais são as particularidades das mobilidades em fretamentos eventuais em ônibus interestaduais? Em que diferem de outros deslocamentos? Tais como: o transporte interestadual regular de passageiros o fretamento contínuo, os deslocamentos no interior de uma mesma unidade federativa, ou ainda o uso de outros modais, como o aéreo. Para isso, cabe, comparar indicadores desses diferentes tipos de mobilidade e refletir sobre os fatores de escolha dos passageiros frente a essas diferentes opções, como: conectividade, flexibilidade, custo, tempo e distância (PALHARES; FRAGA; CASTRO, 2013).

O gráfico a seguir apresenta dados sobre a movimentação de passageiros entre estados brasileiros de acordo com diferentes modalidades de transporte.

FIGURA 1 - MOVIMENTAÇÃO DE PASSAGEIROS ENTRE ESTADOS BRASILEIROS 2010 A 2018

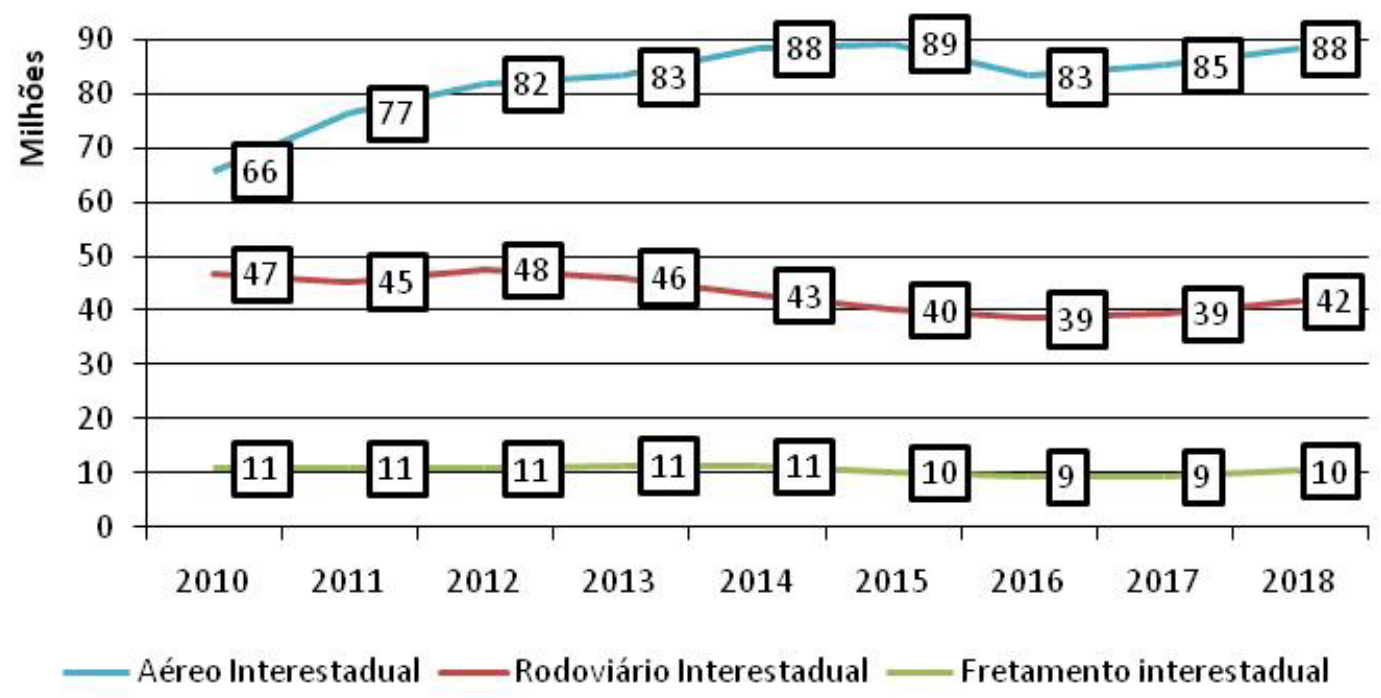

FONTE: Ministério da Infraestrutura (2019)

1 RAFFESTIN, C. Por Uma Geografia do Poder. São Paulo: Ática, 1993 [1980]

2 SOUZA, M. J. O. Território: sobre espaço e poder, autonomia e desenvolvimento. In: Iná Elias de Castro et al (org.). Geografia: conceitos e temas. Rio de Janeiro: Bertrand Brasil, 1995. 
O transporte aéreo é a principal escolha dos brasileiros para viajar entre diferentes unidades federativas (UF). Reflexo das largas distâncias, preço competitivo e concentração populacional nos centros urbanos. Entre 2013 e 2017 há inclusive uma possível substituição entre os modais, com aumento de deslocamentos em avião concomitante ao declínio do transporte rodoviário via linhas regulares. Já os fretamentos interestaduais têm mantido uma demanda relativamente estável, entre 9 e 11 milhões de passageiros por ano. Outro indicador é a taxa de ocupação, ou seja, assentos utilizados por assentos ofertados.

FIGURA 2 - TAXA DE OCUPAÇÃO ENTRE DIFERENTES MODALIDADES DE TRANSPORTE DE 2010 A 2018

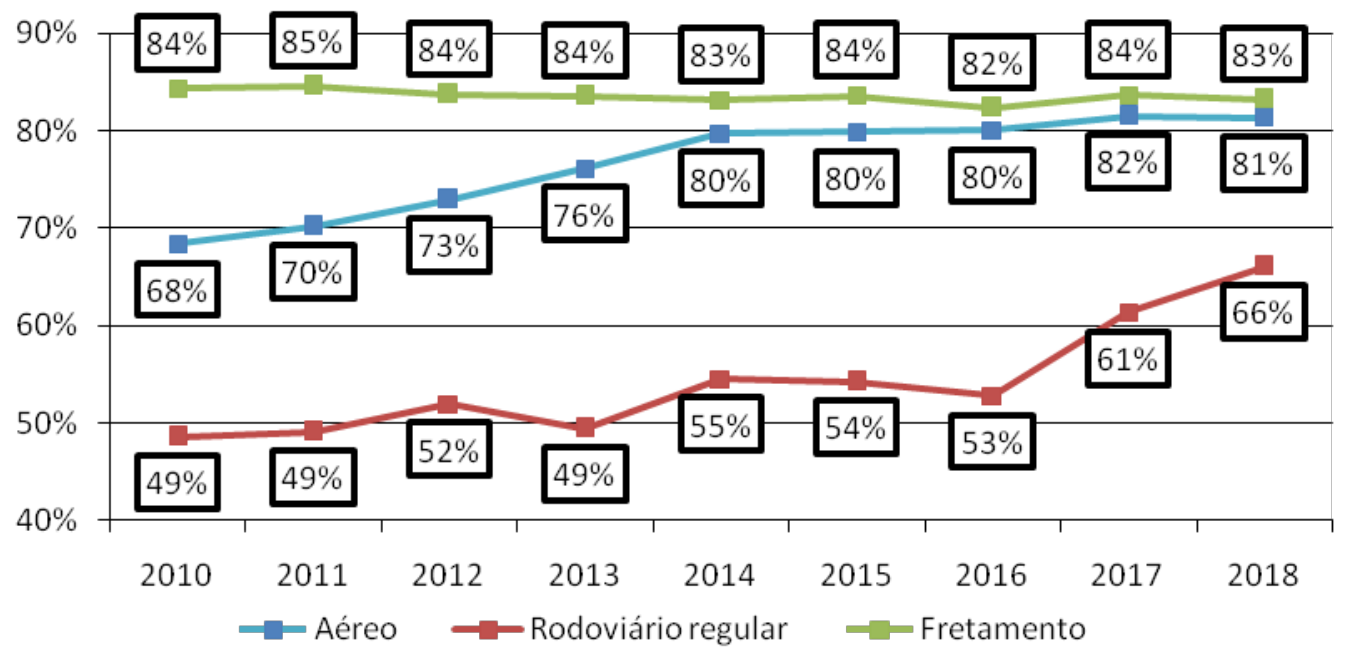

FONTE: Ministério da Infraestrutura (2019)

Os fretamentos interestaduais têm maior taxa de ocupação ( $83 \%$ em média) frente a $54 \%$ das linhas regulares. Essa maior ocupação também reflete uma maior eficiência e preços menores ao consumidor final. Os fretamentos eventuais têm $25 \%$ do número de passageiros das linhas regulares, em um número de viagens que corresponde a $20 \%$ dessas. Já o seu índice de passageiros por quilômetro transportado representa $47 \%$ daquele das linhas regulares.

Contudo, as três modalidades diferem na estrutura de seu mercado. Por seus altos custos de entrada, em termos de capital, tecnologia e especialização técnica, o setor aéreo apresenta uma tendência de concentração. Três empresas (Gol, Latam e Azul) concentram 96\% do número de passageiros transportados (ANAC, 2020).

$\mathrm{O}$ transporte interestadual rodoviário em linhas regulares vem passando por mudanças em sua regulação, de modo a permitir maior concorrência. Ainda assim, no período entre 2009 e 2018 existiam em média 239 empresas com permissão de atuar em linhas interestaduais regulares. Isso, frente à 3.955 estabelecimentos 
autorizados a operar fretamentos. Dada a relativa facilidade de ingresso, o mercado de fretamento eventual tende a ser uma estrutura com grande capilaridade, concorrência, diversificação e com organização de atuação regional. Como caracterizar os deslocamentos em fretamento eventual e o porquê da escolha por essa maneira de transporte?

Como apontam Solha e Braga (2016, p.139):

\begin{abstract}
Embora pouco estudado, o universo do fretamento eventual é parte fundamental do sistema de turismo, apresentando diferentes dinâmicas na composição e na estrutura das viagens. Estes serviços podem garantir a mobilidade de grupos de turistas dentro dos destinos com traslados e passeios, também atendendo à demanda de deslocamento de variados grupos de turistas, em percursos de origem-destino ou mesmo entre destinos. A oferta dos diferentes serviços de transporte turístico rodoviário caracteriza a modalidade de turismo rodoviário. Contudo, em função da capacidade e das características dos veículos pode-se oferecer diferentes experiências de viagem, que atendem a tipos bastante específicos de turistas e destinos. (SOLHA; BRAGA, 2016, p.139)
\end{abstract}

Essas viagens são em circuito fechado e necessitam de autorização da ANTT ou das agências estaduais, como os Departamentos de Estradas de Rodagem (DER), no caso intermunicipal. Assim, diferentemente das linhas regulares, não existem aqui deslocamentos cotidianos. Há ainda o regresso a origem, o que ocorre geralmente em tempo relativamente curto. A escolha das rotas também não advém de alguma determinação da necessidade de conexão, mas exclusivamente pelo interesse da demanda e pela viabilidade econômica da viagem. Assim, geralmente há um custo mais baixo, dada a garantia de maior ocupação do veículo. Além disso, ainda há a combinação com outros serviços, como hospedagem, alimentação e acesso a atrativos.

Nos fretamentos eventuais existe a flexibilidade em relação ao roteiro, adaptado às necessidades do grupo e com a possibilidade de maior conectividade e paradas, se comparado ao transporte ponto a ponto. É uma modalidade apta para viagens multidestino (LUE; CROMPTON; FESENMAIER, 1993). Com frequência, são viagens desenhadas considerando aspectos como: ver o máximo possível no tempo disponível, satisfazer o máximo de preferências em grupos possivelmente heterogêneos, reduzir o risco de insatisfação ao diversificarem-se os destinos visitados (LUE; CROMPTON; FESENMAIER, 1993; TIDESWELL; FAULKNER 1999, BECKEN, 2006).

Observa-se ainda a necessidade de um intermediário, o operador de viagem. Esse desempenha o papel de aglutinar um grupo. Assim, é frequente nesse tipo de mobilidade a interação e a construção de uma relação social entre os passageiros. Ao estudar excursões rodoviárias Baloglu e Shomaker (2001) apontam a busca por segurança, diversão e a interação social na companhia de outros viajantes como elementos característicos da escolha por esse tipo de viagem. Tais aspectos tornam os fretamentos eventuais propícios enquanto porta de ingresso de novos públicos à prática do turismo. Como argumenta Löfgren (2006) ser turista é uma condição que 
deve ser aprendida, requer uma série de competências em relação à disposição de si em um espaço marcado pela alteridade.

Esse intermediário nem sempre é um agente de viagens. Em estudo sobre os fretamentos eventuais no estado de São Paulo, Solha e Luques (2011, s.p.) indicam que há "dois grupos de captadores de viagens, por um lado as pessoas jurídicas representadas por empresas e associações, e por outro as pessoas físicas como motoristas, freelancers e 'Donas Marias' [representantes de grupos com interesse em contratar serviços de fretamento]". Esses intermediários, muitas vezes, são clubes, igrejas, escolas, universidades ou sindicatos, configurando o caráter gregário desse tipo de mobilidade. Os fretamentos eventuais são distintos, tanto da impessoalidade dos deslocamentos em linhas regulares, quanto da familiaridade das viagens em veículo próprio. Além do que, a existência do intermediário torna a distribuição da oferta desse serviço diversa das linhas regulares, tanto do transporte rodoviário quanto aéreo.

Considera-se ainda que as viagens interestaduais ou internacionais são deslocamentos geralmente superiores a três horas, podendo estender-se por vários dias. O valor da mediana dessas viagens em circuito entre 2015 a 2019 foi de 1.000 quilômetros. Já a média - sensível aos valores extremos - foi de 4.248 quilômetros (ANTT, 2018, 2019, 2020).

Em contraste com a maior flexibilidade e privacidade oferecida pelo automóvel próprio ou alugado, os fretamentos têm como vantagens: serem menos cansativos para o motorista; eliminarem preocupações com a condução em local desconhecido; com estacionamento, pedágios, multas; além de não exigir veículo próprio. Em contraste ao modal aéreo, que é mais veloz, os fretamentos eventuais podem ser alternativas mais econômicas, em especial considerando a maior capacidade para o transporte de bagagens - dado que muitas viagens têm compras como objetivo. Além disso, a oferta aérea é concentrada nos grandes centros. Assim, o transporte rodoviário atende melhor municípios distantes de aeroportos, ou cuja conexão com modal aéreo tem menor custo-benefício que o uso exclusivo do ônibus.

Há também ocasiões em que os tipos de transporte se complementam (BECKEN, 2006), com o uso do avião para cobrir trecho maior entre origem e destino e o uso dos fretamentos para explorar a região. Isso parece se aplicar ao caso da região nordeste, dado o destaque para agências receptivas como contratantes de fretamentos.

Analisando essas características compreende-se os fretamentos eventuais enquanto mobilidades com diferentes motivações, em que atuam fatores de escolha com diferentes pesos. É o caso da identidade de grupo e interações sociais em viagens de cunho religioso; do maior limite de bagagem e segurança em viagens para compras; da possibilidade de múltiplos destinos, interação e integração com a paisagem no caso de viagens de lazer. Isso aponta para uma multiplicidade e diversidade dos processos de territorialização dos sujeitos do turismo. Como apresenta Fratucci (2014, p.91): "Cada um dos agentes sociais age e interage entre si e com os demais agentes sociais a partir de lógicas de territorialização distintas, 
quase sempre aleatórias, sazonais e diacrônicas, o que nos impede de pensar o turismo como um sistema fechado ou estático".

Neste sentido, descrever esse espaço articulado pelos sujeitos em suas mobilidades de fretamento eventual é um ponto importante para compreensão de como ocorre essa territorialização do turismo no país, o que pode subsidiar políticas públicas e processos de planejamento e gestão para o setor de turismo.

\section{METODOLOGIA}

A ANTT disponibiliza em seu portal de estatísticas os dados operacionais das autorizações para fretamento eventual a partir de 2013. Algumas das variáveis da base de dados são: número da autorização; identificação da transportadora, identificação da contratante, dados do veículo, valor contratado da viagem, quilometragem total, número de passageiros e informações sobre o itinerário - tais como localidades, datas e sequências dos trechos. Recorda-se que o fretamento eventual é obrigatoriamente um circuito fechado.

A caracterização da distribuição espacial desses fluxos foi realizada a partir da adaptação dos dados para um modelo de origem e destino, frequentemente utilizado no estudo do sistema turístico (FORER; PEARCE, 1984; PEARCE, 1987). Como origem, se estabelece sempre o município de início da viagem e como destinos as diferentes localidades do itinerário. Mesmo que nem todas as localidades cumpram o papel de destino, pois podem ser uma parada técnica, tal opção permite identificar a totalidade dos territórios articulados nessa rede de fretamentos. Além de viabilizar a pesquisa de viagens multidestino, em que não há claramente um destino final, pois, um ponto de origem interage com várias localidades visitadas. Outra opção seria utilizar como referência o início e o final de cada trecho. Entretanto, assim sublinha-se a interação entre locais visitados em sequência, mas perde-se a referência do local de partida da excursão e uma compreensão global da viagem. Também se optou por excluir da análise os trechos de retorno à origem. Essa escolha implicou restringir a pesquisa aos anos de 2016 a 2019, pois não havia a identificação do trecho correspondente em anos anteriores.

Para os quatro anos, 2016 a 2019, obteve-se 207.044 ligações, embora a maior parte com poucos passageiros. Seria inviável realizar uma cartografia temática com tal número de conexões. Optou-se por aplicar diferentes métodos de agrupamento, estabelecer um ponto de corte e trabalhar apenas com as primeiras 3.285 ligações, que representam $56 \%$ do número total de passageiros. Utilizando o plugin Oursins do software QGis foi possível realizar uma cartografia temática da interação espacial promovida pelos fretamentos eventuais. Particularmente, quanto aos mapas, foram representadas as primeiras 300 ligações, correspondendo a $25 \%$ do total do fluxo de passageiros.

Ao categorizar os intervalos do número de passageiros testou-se diferentes métodos de análise de agrupamento: Jenks, Ward e quebras naturais. Adaptou-se os valores das soluções de Ward para aqueles mais próximos às quebras naturais, 
o que permitiu uniformizar a legenda utilizada entre mapas de diferentes anos e com diferentes variáveis. A uniformidade interna entre os diferentes agrupamentos foi confirmada pelo teste de Kruskall-Wallis, disponível no SPSS. O método nãoparamétrico de Spearman foi usado para avaliar a semelhança entre os fluxos de diferentes anos.

Dado a ausência de dados de boa parte dos municípios, as técnicas de Análise Exploratória de Dados Espaciais (ESDA, em inglês), disponíveis no software GeoDa, não apresentaram resultados coerentes.

\section{RESULTADOS E DISCUSSÃO}

Alguns pontos que direcionam essa reflexão sobre fretamentos eventuais interestaduais / internacionais são:

- As medidas de tendência central das variáveis disponibilizadas;

- Os ritmos - dimensão temporal - desses deslocamentos;

- Os principais atores e a estrutura desse mercado;

- As principais origens e destinos e as rotas que concentram público.

Anteriormente, foram apresentados dados comparativos do número de passageiros em fretamento eventual com outras modalidades. A tabela a seguir apresenta indicadores que auxiliam à compreensão desse tipo de mobilidade e de suas implicações espaciais, econômicas e sociais.

TABELA 1 - CARACTERIZAÇÃO DOS FRETAMENTOS EVENTUAIS ENTRE 2016 E 2019

\begin{tabular}{|c|c|c|c|c|c|c|c|}
\hline Ano & $\begin{array}{c}\text { Passageiros } \\
\text { (n.) }\end{array}$ & $\begin{array}{l}\text { Licenças } \\
\text { (n.) }\end{array}$ & $\begin{array}{c}\text { Contratantes } \\
\text { (n.) }\end{array}$ & $\begin{array}{c}\text { Transportadoras } \\
\text { (n.) }\end{array}$ & $\begin{array}{l}\mathrm{Km} \\
\text { média }\end{array}$ & $\begin{array}{c}\mathrm{Km} \\
\text { mediana }\end{array}$ & $\begin{array}{l}\text { Média valor } \\
\text { Nota fiscal }\end{array}$ \\
\hline 2016 & 9.433 .398 & 269.820 & 89.881 & 4.034 & 8.651 & 1.000 & $\mathrm{R} \$ 5.341,84$ \\
\hline 2017 & 9.474 .777 & 282.827 & 95.787 & 4.406 & 2.822 & 1.000 & $\mathrm{R} \$ 4.922,08$ \\
\hline 2018 & 10.430 .659 & 313.230 & 102.133 & 23 & 2.941 & 1.000 & $\mathrm{R} \$ 3.875,24$ \\
\hline 2019 & 11.924 .184 & 363.744 & 45.492 & 5.823 & 2.580 & 1.000 & $\mathrm{R} \$ 5.060,74$ \\
\hline
\end{tabular}

FONTE: O autor baseado em ANTT (2016, 2017, 2018, 2019)

Entre 2016 e 2019 houve tendência de crescimento, tanto em passageiros, quanto em licenças autorizadas. Nota-se uma grande amplitude entre os valores de quilometragem média, em especial do ano de 2016 para os outros. No entanto, a mediana é a mesma para os quatro anos. Ao contrário de circuitos de largas distâncias, que deslocam a média para cima, as viagens de mil quilômetros, mais frequentes, são compatíveis com deslocamentos entre estados limítrofes. 
Há, ainda, maior número de contratantes do que empresas transportadoras. O mercado da intermediação é pulverizado e dinâmico. Considerando os contratantes dos quatro anos encontramos 219.784 CNPJs ou CPFs que tiveram viagens autorizadas. Avaliando os que executaram pedidos em todos os anos, o número reduz para 11.394, indicando elevado número de intermediários que exercem esse papel de modo eventual e menos agentes profissionais dedicados à intermediação do fretamento eventual de modo consistente. Já, o coeficiente de Spearman permite verificar a variação anual do posicionamento dessas empresas, tanto na quantidade de passageiros transportados quanto do valor pago em notas fiscais.

TABELA 2- CORRELAÇÃO DA VARIAÇÃO ANUAL DA SOMA DO NÚMERO DE PASSAGEIROS E DO VALOR DAS NOTAS FISCAIS EMITIDAS POR CONTRATANTES DE FRETAMENTO EVENTUAL

\begin{tabular}{|c|c|c|c|c|c|c|c|c|}
\hline \multicolumn{9}{|c|}{ Número de passageiros } \\
\hline$\rho$ & 2016 & 2017 & 2018 & 2019 & 2016 & 2017 & 2018 & 2019 \\
\hline 2016 & 1 &, $696^{\star \star}$ &, $637^{\star \star}$ &, $466^{\star \star}$ & 1 &, $751^{\star \star}$ &, $676^{\star \star}$ &, $565^{\star \star}$ \\
\hline 2017 &, $696^{\star \star}$ & 1 &, $728^{\star \star}$ &, $534^{\star \star}$ &, $751^{\star \star}$ & 1 &, $762^{\star \star}$ &, $624^{\star \star}$ \\
\hline 2018 &, $637^{\star \star}$ &, $728^{\star \star}$ & 1 &, $597^{\star \star}$ &, $676^{\star \star}$ &, $762^{\star \star}$ & 1 &, $699^{\star \star}$ \\
\hline 2019 &, $466^{\star \star}$ &, $534^{\star \star}$ &, $597^{\star \star}$ & 1 &, $565^{\star \star}$ &, $624^{\star \star}$ &, $699^{\star \star}$ & 1 \\
\hline \multicolumn{3}{|c|}{ A correlação é significativa no nível 0,01 (2 extremidades). } & \\
\hline
\end{tabular}

FONTE: O Autor (2021).

Existe correlação positiva significativa para todos os anos em ambas as medidas indicando certa regularidade na posição desses atores, embora haja variações. É o caso de 2019, cuja baixa no índice pode ser reflexo de concentração no número de contratantes, que se reduziu de 102 mil para 45 mil. As empresas apresentam posições distintas de acordo com a medida. Existem as que se destacam pelo grande número de passageiros, geralmente em deslocamentos mais curtos, e as que têm maior valor da nota fiscal, em geral com faturamento maior e viagens mais longas.

O mercado dos operadores de viagens em fretamento eventual é também pulverizado. No conjunto dos quatro anos, a empresa com maior número de passageiros transportados representa apenas $1,5 \%$ do total de viajantes. 
TABELA 3 - RAZÃO SOCIAL DOS PRINCIPAIS CONTRATANTES DE FRETAMENTOS EVENTUAIS E PASSAGEIROS TRANSPORTADOS DE 2016 A 2019

\begin{tabular}{|c|c|c|c|c|c|}
\hline RAZÃO SOCIAL & 2016 & 2017 & 2018 & 2019 & MÉDIA \\
\hline LUCK VIAGENS E TURISMO LTDA & 40.407 & 52.109 & 83.841 & 37.410 & 53.442 \\
\hline MAR \& SOL VIAGENS LTDA ME & 34.471 & 38.677 & 39.036 & 14.051 & 31.559 \\
\hline $\begin{array}{c}\text { CVC BRASIL OPERADORA E AGÊNCIA DE } \\
\text { VIAGENS S.A. }\end{array}$ & 29.513 & 35.451 & 37.802 & 21.440 & 31.052 \\
\hline AGT TURISMO EIRELI & 27.126 & 26.574 & 27.633 & 6.174 & 21.877 \\
\hline SUL AMERICA TRANSPORTES LTDA - ME & 9.649 & 23.674 & 46.470 & 7.384 & 21.794 \\
\hline LUIZ WANDERLEY TISSI & 17.042 & 22.428 & 26.036 & 10.005 & 18.878 \\
\hline TRANSPORTE E TURISMO LTDA & 12.810 & 14.698 & 24.215 & 15.817 & 16.885 \\
\hline SENHUK TOUR VIAGENS EIRELI- ME & 26.624 & 23.001 & 13.903 & 2.898 & 16.607 \\
\hline DHL LOGISTICS BRASIL LTDA & 9.395 & 23.176 & 17.554 & 12.740 & 15.716 \\
\hline BRASTOUR TURISMO E COMPRAS & 15.060 & 20.479 & 21.701 & 3.262 & 15.126 \\
\hline AUTOVIAÇÃO GADOTTI LTDA & 735 & 21.991 & 23.789 & 8.356 & 13.718 \\
\hline MARILETE DOS SANTOS VARGAS & 13.332 & 15.852 & 17.690 & 6.250 & 13.281 \\
\hline COSTAZUL TURISMO E RECEPTIVO LTDA & 14.191 & 12.520 & 15.401 & 10.843 & 13.239 \\
\hline ADRIANA CARDOSO SILVA & 7.859 & 8.769 & 16.747 & 13.779 & 11.789 \\
\hline TRANSTOP LOCAÇÃO DE VEÍC. E MAQ. LTDA & 20.579 & 13.861 & 8.270 & 46 & 10.689 \\
\hline MD TUR - MAURI JOSE DUTRA JUNIOR & 7.502 & 18.137 & 10.867 & 4.722 & 10.307 \\
\hline MARIA APARECIDA DE SOUZA & 2.605 & 9.440 & 22.610 & 3.920 & 9.644 \\
\hline MUTUM PRETO VIAGENS E TURISMO & 13.841 & 9.708 & 11.831 & 2.563 & 9.486 \\
\hline TROPICANA TURISMO & 9.778 & 8.728 & 12.519 & 4.902 & 8.982 \\
\hline
\end{tabular}

FONTE: O autor baseado em ANTT (2016, 2017, 2018, 2019)

A tabela apresenta os vinte principais contratantes em número de passageiros no período. Diante da impossibilidade de apresentar este universo de 11.394 organizações, optou-se por essa restrição, que representa apenas 4,4\% do total de passageiros transportados.

Ao buscar a forma como as diferentes empresas descrevem sua atuação em suas páginas eletrônicas, é possível notar organizações de diferentes origens e perfis. Todavia, destaca-se a atuação regionalizada. Há, por exemplo, empresas focadas no turismo receptivo como as nordestinas Luck, Costa Azul e Tropicana. Outras dedicadas em atender clientes de seu local de origem em viagem para outros estados, como a mineira Mar \& Sol e a capixaba Mutum Preto. Há também o caso de empresas com ofertas especializadas em turismo de compras como a mineira Senhuk e as fluminenses Brastour e AGT.

Analisando-se a lista completa, percebe-se além de operadoras de turismo intermediários como: instituições de ensino (Universidades Estaduais, Federais e Institutos Federais), municípios (custeando deslocamentos para tratamentos de 
saúde), a Marinha do Brasil, o SESC (em programas de Turismo Social), além de grupos religiosos, clubes esportivos e Sociedades Anônimas (Nissan, Longping biotecnologia, Fibria celulose) com unidades em diferentes estados, que utilizam o fretamento de modo esporádico.

Outrossim, em 2018 e 2019 a empresa com maior número de passageiros transportados é a Buser Brasil, OTA que intermedia o aluguel de transporte intermunicipal via aplicativo. Ela representa um novo modelo de negócios, que pode ganhar escala nacional e transformar o mercado do transporte rodoviário, semelhante ao ocorrido com a mobilidade intraurbana. Embora atualmente encontre resistência da ANTT (KAFRUNI, 2021).

Mas, qual a distribuição espacial das rotas em fretamento eventual? Analisando de modo uniforme os trechos com mais de 3.000 passageiros nota-se uma concentração no centro-sul do país e outra na região nordeste. A região norte praticamente não conta com ligações intra-regionais, a exceção de Manaus (AM) - Boa Vista (RR).

\section{FIGURA 3 - LIGAÇÕES EM FRETAMENTOS EVENTUAIS}

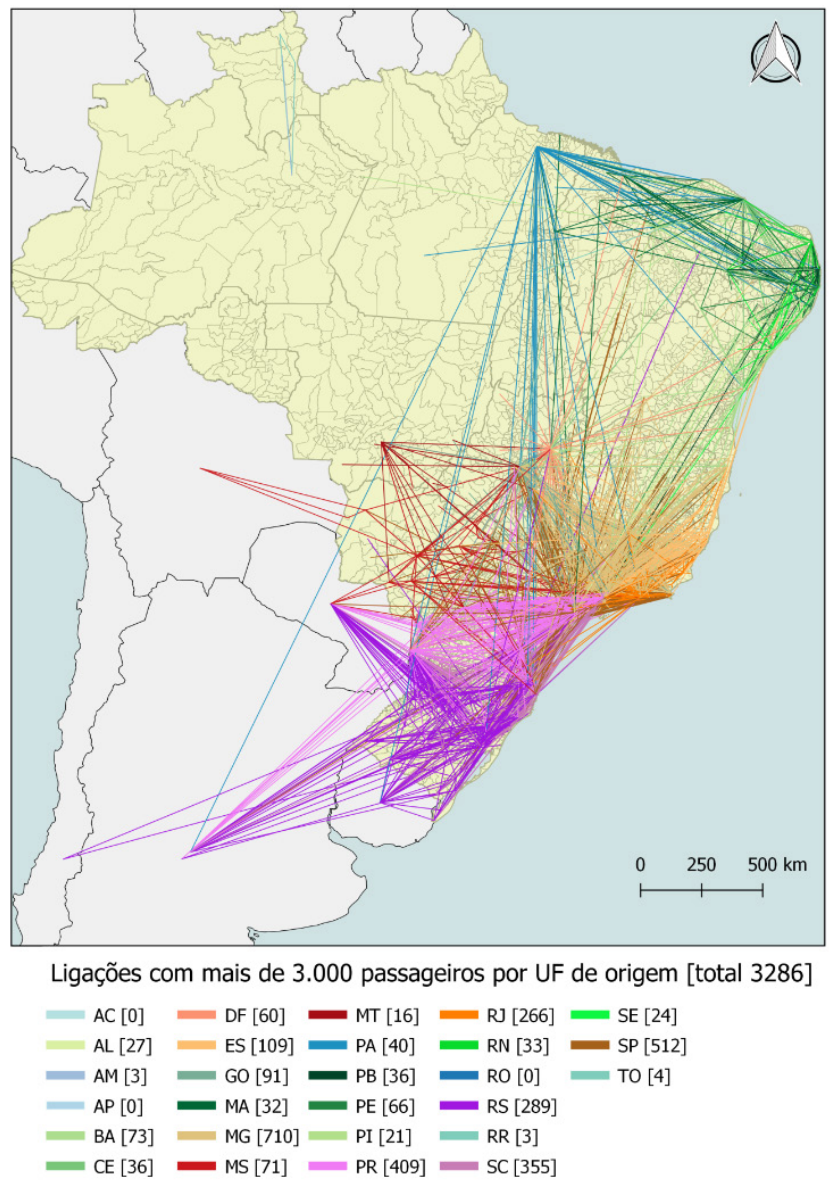

FONTE: O autor baseado em ANTT $(2016,2017,2018,2019)$ e IBGE $(2019)$. 
Existe a tendência de maior articulação entre unidades federativas vizinhas e de ligações entre espaços com maior concentração populacional. Além disso, também influenciam nesse quadro fatores como a existência, ou não, de boa infraestrutura rodoviária, a distância / tempo de deslocamento, e a oferta de transporte aéreo.

A região Sudeste concentra o maior número de ligações. O destaque é Minas Gerais, estado com mais divisas na região e com maior número de ligações (710). No Nordeste as ligações concentram-se no litoral. Já no Centro-Oeste é maior o número de vínculos para fora da região do que entre seus estados, em particular ligando-o ao Sudeste. Na região Sul há maior vínculo com países vizinhos. Na região Norte, dada a predominância do modal hidroviário, o fretamento tem números pouco expressivos. Há, por exemplo, dez vezes mais passageiros viajando do Rio Grande do Sul com destino ao Peru, do que partindo do Acre, estado vizinho àquele país. Não obstante, Belém (PA), apesar de afastada dos pontos de concentração de fluxo, está conectada tanto com o núcleo do Nordeste, quanto com a região central do país e com os vizinhos platinos.

FIGURA 4 - SÉRIE TEMPORAL MENSAL DO NÚMERO DE PASSAGEIROS EM FRETAMENTOS EVENTUAIS DE 2016 A 2019

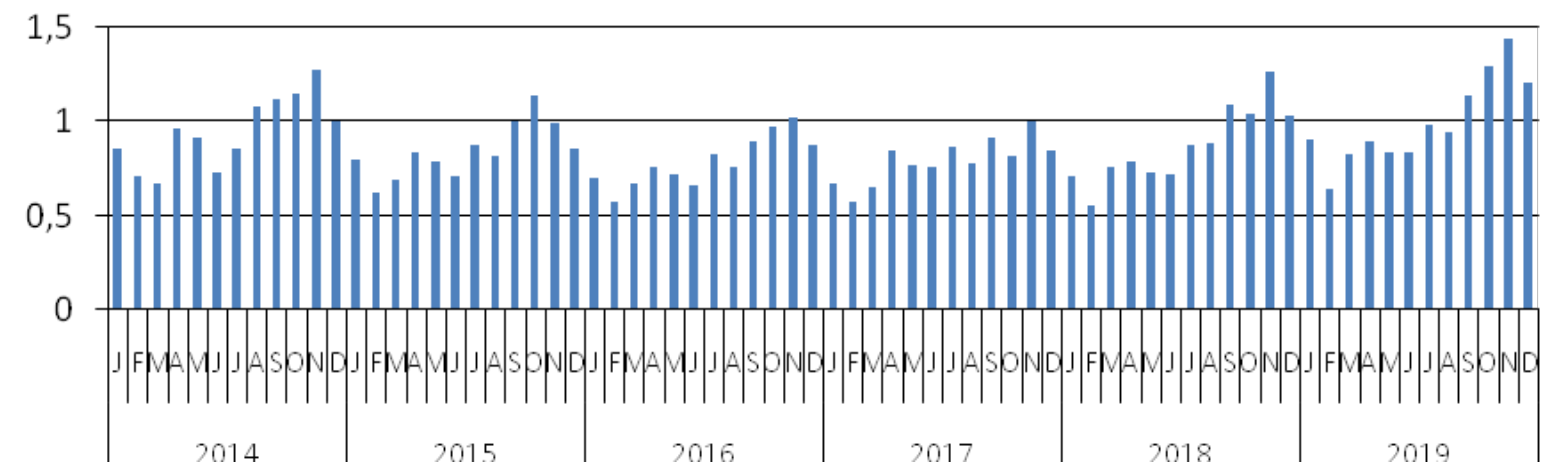

FONTE: O autor baseado em ANTT $(2016,2017,2018,2019)$.

Quanto à distribuição temporal dos fretamentos eventuais é recorrente a concentração no segundo semestre. Destaca-se novembro, único mês com dois feriados nacionais e próximo ao Natal - vale recordar que compras são uma motivação nos fretamentos eventuais. Assim, o uso da modalidade parece sensível aos feriados. Além disso, os feriados, pelo calendário em comum, também parecem otimizar a formação de grupos para viagem, correspondendo a ideia de viagens de curta duração e em grupo. Por outro lado, nos meses de verão, período de férias escolares e alta demanda por serviços turísticos, há uma baixa nos fretamentos eventuais. 
FIGURA 5 - SÉRIE TEMPORAL DIÁRIA DO NÚMERO DE PASSAGEIROS EM FRETAMENTOS EVENTUAIS DE 2016 A 2019

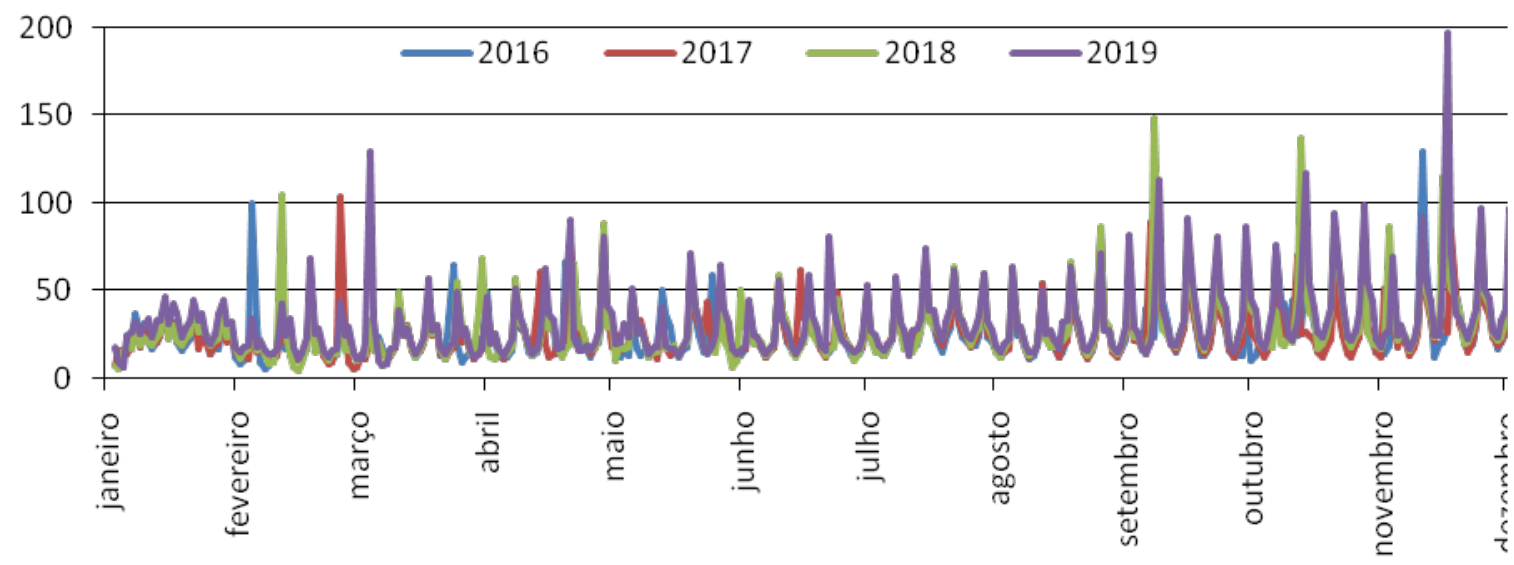

FONTE: O autor baseado em ANTT $(2016,2017,2018,2019)$.

Visualizando-se a distribuição diária das séries, alinhadas para que haja correspondência entre os dias da semana nos diferentes anos, os feriados são destaque. No primeiro semestre, boa parte dos feriados não tem data fixa no calendário, vide os diferentes picos de demanda ligados ao carnaval. Outro ponto sobre o ritmo dos fretamentos é a tendência de saídas nas sextas-feiras, ou no dia anterior aos feriados, e o baixo número de viagens durante o restante da semana. 
Fluxo de passageiros em fretamento ocasional

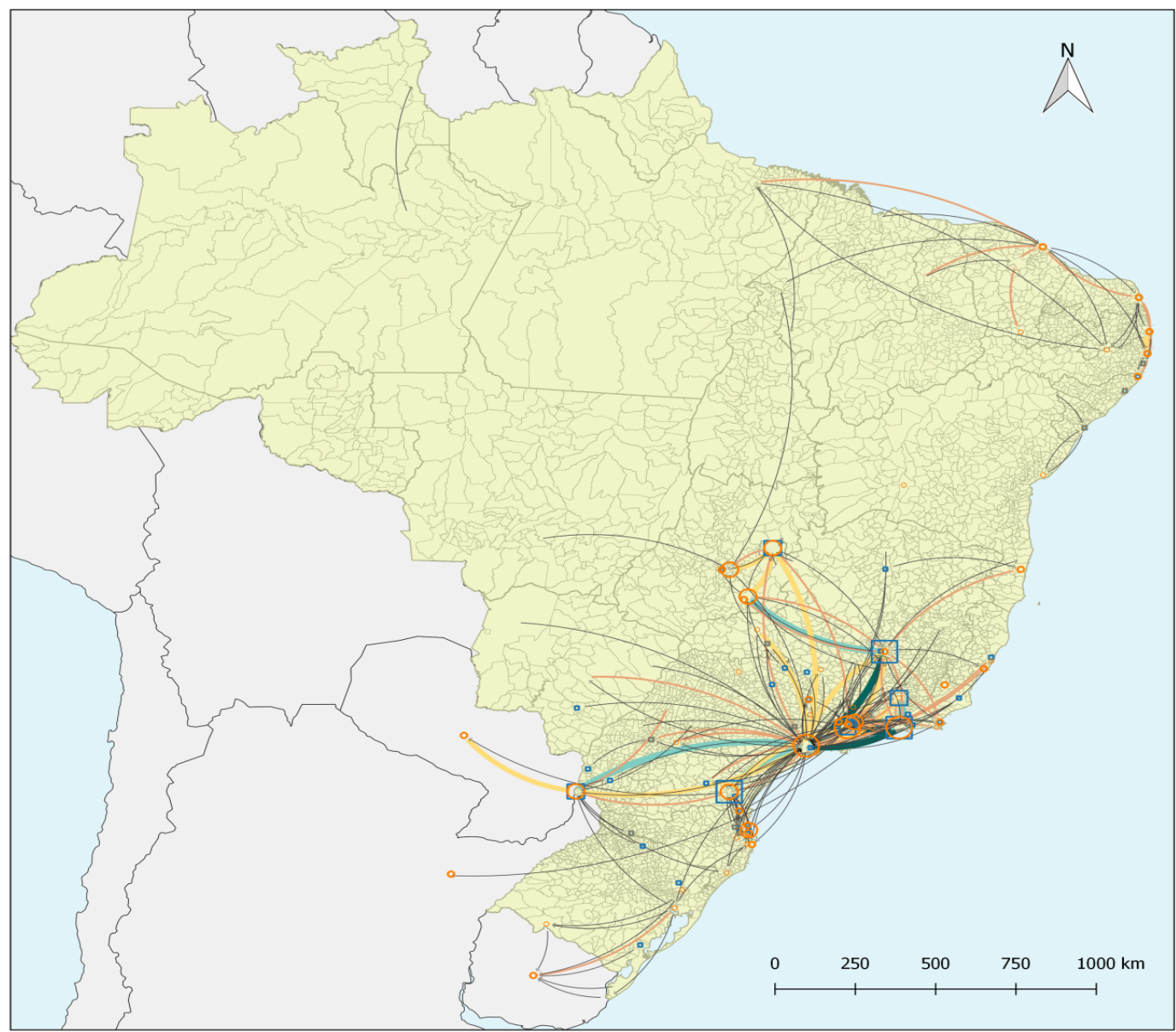

Legenda

Média anual de passageiras

De 120 a 180 mil (f.4)

De 80 a 120 mil (f.6)

- De 40 a 80 mil (f. 16 )

- De 20 a 40 mil (f.57)

De 8,5 a 20 mil (f. 212$)$

Destinos Origens

De 500 mil a 2,3 milhões (f.3) $\square$ De 500 mil a 1,1 milhão (f.3)

De 250 a 500 mil (f.7)

$\square \quad$ De 250 a 500 mil (f.7)

De 100 a 250 mil (f.22)

De 50 a 100 mil (f.34) De 10 a 50 mil (f.219)

- De100 a 250 mil (f.18)

- De 50 a 100 mil (f. 38)

De 10 a 50 mil (f.274) Fonte: elaborado cam base em ANTT $(2016,2017,2018,2019)$ e IBGE(2019).

FONTE: O autor baseado em ANTT $(2016,2017,2018,2019)$ e IBGE (2019).

A intensidade dos fluxos, pode ser avaliada a partir da figura 6, que a representa com a utilização da média do número de passageiros entre 2016 a 2019 de cada trecho. Para avaliar a correlação entre os diferentes anos aplicamos o teste de Spearman. 
TABELA 4 - CORRELAÇÃO ENTRE TRECHOS DE FRETAMENTOS EVENTUAIS DE 2016 A 2019

\begin{tabular}{|c|c|c|c|c|c|}
\hline$\rho$ & 2016 & 2017 & 2018 & 2019 & Média \\
\hline 2016 & 1 & ,809** &, $185^{\star *}$ &, $641^{\star *}$ &, $681^{* *}$ \\
\hline 2017 & $809^{* *}$ & 1 & $186^{* *}$ &, $711^{\star *}$ &, $708^{* *}$ \\
\hline 2018 &, $185^{\star *}$ &, $186^{* *}$ & 1 &, $163^{* *}$ &, $694^{\star *}$ \\
\hline 2019 &, $641^{* *}$ &, $711^{\star \star}$ &, $163^{\text {** }}$ & 1 &, $662^{* \star}$ \\
\hline Média &, $681^{\star *}$ &, $708^{* *}$ & ,694 & ,662 & 1 \\
\hline
\end{tabular}

Dado o interesse na caracterização geral dos fluxos, a correlação de 0,66 ou superior - entre os quatro anos e a média, corrobora a opção dessa como medida referência na construção da cartografia. Entretanto, sublinha-se que existem variações na comparação anual entre os fluxos de cada trecho. Exemplo dado pela fraca correlação entre 2018 e os outros anos, cuja explicação requer um olhar mais detalhado.

A flutuação em termos de origem / destino e a intensidade desses fluxos entre os diferentes anos pontua a própria natureza 'eventual' dessas mobilidades. Eventos esportivos e culturais, calendários de feriados, festas religiosas e conjuntura econômica são aspectos que alteram a distribuição espacial da demanda por viagens fretadas. Embora os trechos com maior número de passageiros estejam presentes todos os anos, mesmo que em intensidades distintas.

Os fluxos de fretamento eventual interestadual com maior número de passageiros são: de Belo Horizonte (MG) e do Rio de Janeiro (RJ) para São Paulo (SP); e do Rio de Janeiro (RJ) para Aparecida (SP). Ao pesquisar sobre os fretamentos no estado de São Paulo, Solha e Braga (2016) também apontam Aparecida como o principal destino de fretamentos intermunicipais naquele estado.

$\mathrm{Na}$ categoria de 80 a 120 mil passageiros anuais, há o movimento de Foz do Iguaçu (PR) e Curitiba (PR) para São Paulo (SP). A direção do fluxo pode ser surpreendente, e parece inserir as cidades paranaenses na polarização do principal centro de compras do país. De São Paulo (SP) e Juiz de Fora (MG) para o Rio de Janeiro (RJ), e de Belo Horizonte (MG) para Caldas Novas e Rio Quente (GO), que é superior ao da capital mineira rumo ao litoral, com fluxos dispersos entre diferentes destinos. Ambas cidades goianas têm fluxo médio anual de 108 mil passageiros belohorizontinos, enquanto que o litoral soma em média 106 mil passageiros, em dez destinos que incluem as capitais fluminense e capixaba.

$\mathrm{Na}$ categoria de 40 a 80 mil passageiros destaca-se: Belo Horizonte (MG), Curitiba (PR) para Aparecida (SP). Brasília (DF), Uberlândia (MG), Juiz de Fora (MG) e Volta Redonda (RJ) para São Paulo (SP). São Paulo para Foz do Iguaçu (PR). Foz do Iguaçu (PR) para o Paraguai. Brasília (DF) para Caldas Novas (GO) e Goiânia (GO). Ipojuca (PE) para Maragogi (AL) e Recife (PE) para João Pessoa (PB). 
$\mathrm{Na}$ classe entre 20 e 40 mil passageiros estão compreendidos movimentos de cidades importantes do interior do Paraná e Campo Grande (MS) para São Paulo (SP). De Belo Horizonte para destinos litorâneos como Porto Seguro (BA) e Cabo Frio (RJ). De São Paulo (SP) para Arraial do Cabo (SP) e de Juiz de Fora (MG) para Cabo Frio (RJ). Na região sul destacam-se ainda os fluxos de Porto Alegre (RS) para o Uruguai, e de Curitiba (PR) para Penha (SC) e Joinville (SC). Na região Nordeste, Fortaleza (CE) é um ponto de convergência dos fluxos de Belém (PA), Teresina (PI) e Natal $(R N)$. Já Natal $(R N)$ apresenta-se como um pólo emissor. Além de Fortaleza (CE), há movimento em direção à João Pessoa (PB) e ao Recife (PE). Outro movimento é de Recife (PE) para Maragogi (AL). No agreste ainda cabe apontar a importância de Santa Cruz do Capibaribe (PE), pólo de confecções que atrai movimento de outros estados.

Os dados permitem caracterizar tais fluxos quanto ao volume de passageiros. No entanto, uma compreensão mais fina em relação a motivação que gera esses movimentos e as significações dessas mobilidades requerem um olhar mais atento à realidade que cada linha representa.

O destino com maior fluxo de passageiros é Aparecida (SP), apontando para importância do turismo religioso e sua opção pelos fretamentos eventuais. Outros destinos que também recebem um importante número de visitantes devido a demonstrações de fé católica são Belém (PA), Juazeiro do Norte (CE), Canindé (CE), Nova Trento (SC) e Trindade (GO), essa também conhecida por ser um pólo do setor de vestuário.

Há também a conexão rumo aos polos de compras. O fretamento eventual apresenta vantagem em relação a outras opções de transporte, pelo custo, capacidade de frete e segurança. Alguns destinos a serem citados neste sentido são Foz do Iguaçu, que recebe um fluxo disperso de municípios do norte do Rio Grande do Sul e sul de São Paulo, e a já mencionada Santa Cruz do Capibaribe (PE). Há, ainda, o movimento dos estados de Mato Grosso e Mato Grosso do Sul para São Paulo.

Outro destaque neste conjunto de dados é a importância da conexão entre capitais. Notam-se dois conjuntos, o das ligações da região centro-sul do país e os vínculos entre as capitais nordestinas. As metrópoles caracterizam-se pela 'concentração da diversidade', logo, essa interação pode ter diferentes motivos, tais como: eventos esportivos, culturais e religiosos, visita a amigos e parentes, concursos públicos, compras e / ou lazer. A própria diversidade de razões é um fator para que tais fluxos sejam importantes. No entanto, a ligação entre as capitais nordestinas apresenta influência de uma população que chega à região pelo modal aéreo e desloca-se internamente por meio de fretamento. Isso é corroborado pela presença de contratantes posicionadas como agências de receptivo. $O$ mesmo não ocorre nas conexões entre Curitiba, Brasília, São Paulo, Rio de Janeiro e Belo Horizonte.

O movimento inter-metropolitano também não apresenta o caráter complementar que existe entre cidades pertencentes a diferentes classes na hierarquia urbana. São Paulo (SP), como metrópole nacional, acolhe fluxos de diferentes regiões do país, mesmo fora de sua área de influência imediata, em especial de municípios de médio 
porte. Isso não ocorre com as outras metrópoles brasileiras, à exceção de Brasília (DF), embora em escala bem inferior e por uma razão diversa, ser a capital política do país. Outro movimento de complementaridade são as interconexões regionais que ultrapassam as divisas estaduais, como de Joinville (SC) para Curitiba (PR), de Juiz de Fora (MG) para o Rio de Janeiro (RJ), entre municípios do triângulo mineiro e norte de São Paulo, bem como do Oeste de Minas para o Distrito Federal (DF).

Quanto às viagens de caráter recreativo, destacam-se as cidades vizinhas de Rio Quente (GO) e Caldas Novas (GO), estâncias termais com resorts. Ainda em Goiás, municípios com atrativos de lazer próximos ao DF. Além do esperado movimento em direção ao litoral em outros estados, como o de Curitiba (PR) e São Paulo (SP) para Balneário Camboriú (SC) e região, de Belo Horizonte (MG) para Cabo Frio (RJ) e Porto Seguro (BA).

Nota-se, aliás, o baixo número de excursões para Bahia, em que pese a forte especialização turística do litoral daquele estado (RAGAGNIN PIMENTEL; PEREIRA, 2021). O que, por um lado, dá a entender sua forte dependência em relação ao modal aéreo, e por outro, sublinha o caráter intra-regional dos fluxos rodoviários em fretamento. Ainda no Nordeste nota-se um movimento importante entre destinos conhecidos, como a interação entre Porto de Galinhas, em Ipojuca (PE), e Maragogi (AL).

Destaca-se a baixa representatividade de destinos Sol \& Praia frente a capacidade de sua oferta e demanda. Seria o fretamento eventual mais adequado a destinos urbanos, ou mais aptos a demanda por viagens curtas, como aquelas de feriados? Essa concentração dos fluxos inter-metropolitanos questiona tanto o modelo clássico de Christaller (1964), em que os núcleos urbanos são origem dos fluxos à periferia de clima agradável ou águas recreativas, quanto à tirania das localidades costeiras descrita por Cazes (1992), ao perceber a onipresente concentração de investimentos turísticos no litoral nos planos de turismo no terceiro mundo, ignorando e até mesmo subordinando outras formas de turismo.

Cabe ainda considerar, de modo separado, as principais origens e destinos desses fretamentos. Isso porque muitas vezes o volume saindo, ou partindo, de algum município pode estar disperso em uma série de ligações, e não se destaca quando a análise está centrada no volume das conexões. 

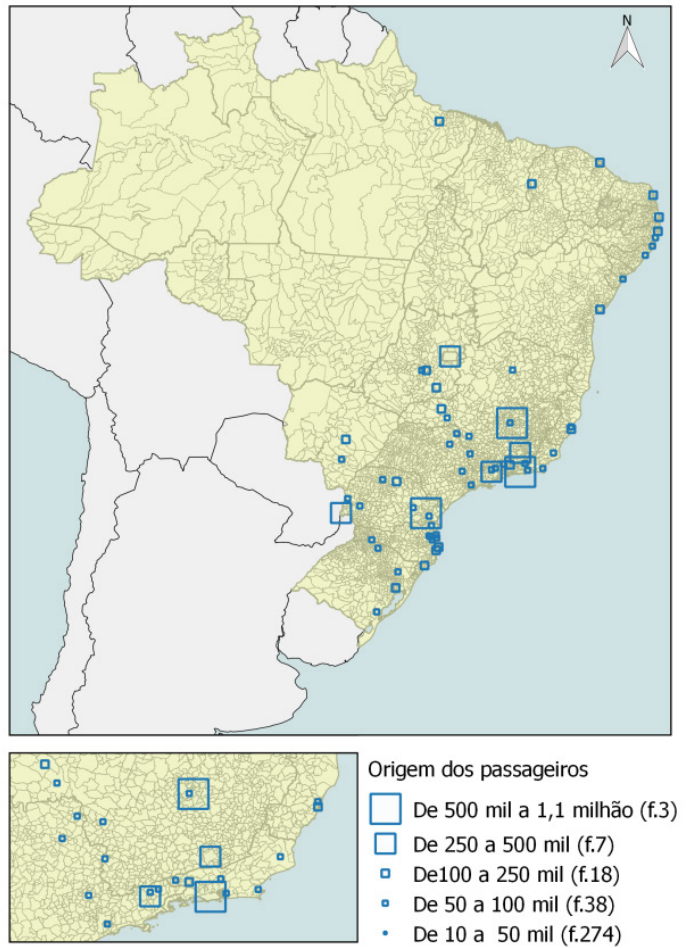
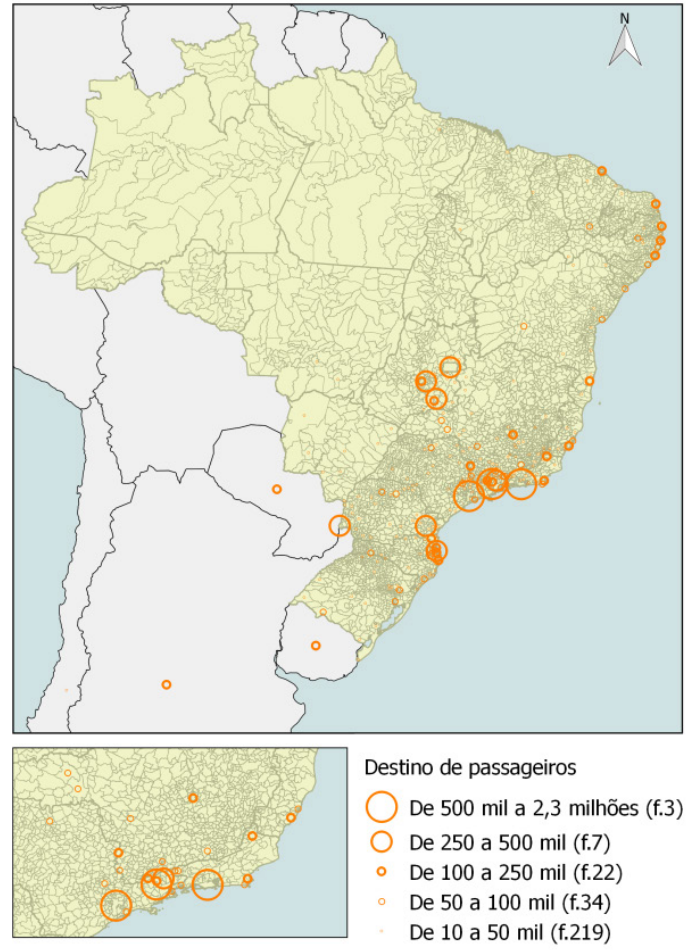

FONTE: O autor baseado em ANTT $(2016,2017,2018,2019)$ e IBGE (2019).

A figura 7 indica o número médio de passageiros de fretamentos eventuais em seus municípios de origem e nos municípios de destino. Há aspectos em comum entre os dois quadros: a já destacada presença das metrópoles, a ausência da porção noroeste do país e a recorrência de muitos municípios. Medindo o vínculo entre as duas variáveis a partir de Spearman, obtém-se $\otimes=0,904$, em um nível de significância de 0,001 . Sinalizando que, em boa parte, são as mesmas localidades que emitem e que recebem os fretamentos, podendo haver inclusive uma interação espacial de mão-dupla.

Todavia, analisando os maiores movimentos em ambos os quadros também se observam diferenças. A mais evidente é a presença de países do Mercosul apenas no mapa de destinos, dado o registro no sistema da ANTT das viagens que partem do Brasil, mas não das com origem nos países vizinhos. Outro ponto, é a maior presença de origens de viagem no interior do país, quando comparado ao quadro dos destinos. Destacam-se os eixos próximos às divisas estaduais, no sentido noroeste-sudeste: de Goiás a São Paulo, do Mato Grosso do Sul ao Rio Grande do Sul e ao Paraná.

Há também municípios caracterizados como emissores, cuja representatividade é menor enquanto destino de passageiros, tais como Belo Horizonte (MG), Juiz de Fora (MG) e Curitiba (PR). Por outro lado, municípios como Caldas Novas (GO), 
Balneário Camboriú (SC) e São Paulo (SP) têm papel destacado enquanto destino. Especificamente as principais origens são Rio de Janeiro (RJ), Belo Horizonte (MG) e Curitiba (PR), enquanto os principais destinos são Aparecida (SP), São Paulo (SP) e Rio de Janeiro (RJ).

\section{CONCLUSÃO}

O mercado doméstico é o principal impulsionador do turismo no Brasil. Todavia, dada à magnitude e diversidade do país, a compreensão dessa dinâmica em uma leitura nacional é um desafio. Este estudo exploratório buscou caracterizar as mobilidades em fretamento eventual interestadual e internacional a partir de dados abertos disponibilizados pela ANTT. Consideraram-se especificidades desse tipo de mobilidade como: sua estrutura de mercado, sua distribuição espacial, ritmos e variação temporal de sua demanda. Foram identificados os principais fluxos de viagens, analisados em termos de sua direção e intensidade. Resultados aptos a subsidiarem políticas de turismo e de transportes. Embora por seu caráter exploratório, o texto não apresente modo explícito o vínculo que tais políticas exercem nas mobilidades investigadas e vice-versa.

O estudo permite uma melhor compreensão sobre como se articulam os territórios-rede do turismo nacional (FRATUCCI; MORAES; ALLIS, 2015).

Em síntese, é possível apontar que os fretamentos eventuais interestaduais têm especificidades frente a outras modalidades de transporte tais como: a importância do papel desempenhado pelo organizador das viagens, a necessidade de formar grupos para viajar, a interação entre passageiros, e uma relação de complementariedade/ concorrência com o modal aéreo. Tais características tornam o volume de passageiros em fretamentos particularmente sensível ao calendário de feriados e a variações na conjuntura. Não obstante, existem conexões recorrentes entre os diferentes anos, as quais o estudo buscou caracterizar em suas distintas intensidades e direções. Há destaque para os fluxos intermetropolitanos, cujas motivações têm razões diversas. Nota-se dois polos de conexões, um no Centro-Sul do país e outro na região Nordeste. Além disso, outros tropismos importantes que orientam esses fluxos são: compras, viagens religiosas e a lazer. Embora seja notável o pouco uso deste tipo de mobilidade para destinos de sol \& praia. Outras características dos fretamentos eventuais interestaduais é a concentração das viagens entre unidades federativas limítrofes, e a ênfase da atuação de empresas locais em um mercado pulverizado.

Ao contemplar a escala nacional, este trabalho contribui para transcender o caráter pontual dos estudos de caso e análises regionais. É original ao propor uma metodologia para interpretar uma base de dados até então ausente da literatura científica sobre Turismo no Brasil. Ao propor um panorama inicial desses dados, certas opções metodológicas na organização, recorte e análise do dataset podem ser questionadas por sua arbitrariedade. A riqueza da fonte permite estudos futuros, temas possíveis são: características e particularidades dos mercados locais; traçados de roteiros - tema clássico no estudo da circulação turística; e fatores para inserção de 
localidades em viagens multidestinos. Encoraja-se maior investimento dos estudos turísticos brasileiros na análise de bases de dados secundários de acesso aberto.

\section{REFERÊNCIAS}

AGÊNCIA NACIONAL DA AVIAÇÃO CIVIL (ANAC). Anuário do Transporte Aéreo Gráficos e Tabelas 2019. Brasília: 2020. Disponível em: < https://www.gov.br/anac/ pt-br/pt-br/assuntos/dados-e-estatisticas/anuario/2019.zip> . Acesso em: 25 ago. 2021.

AGÊNCIA NACIONAL DE TRANSPORTES TERRESTRES (ANTT). Dados operacionais de fretamento eventual interestadual/internacional 2016, 2017, 2018, 2019. Disponível em: <https://dados.antt.gov.br/dataset?tags=fretamento >. Acesso em: 28 out. 2020

BALOGLU, S.; SHOMAKER, S. Prediction of Senior Travelers' Motorcoach Use from Demographic, Psychological, and Psychographic Characteristics, Journal of Travel Research, v. 40, n.1, p. 12-18, 2001.

BECKEN, S. Towards Sustainable Tourism Transport: An Analysis of Coach Tourism in New Zealand, Tourism Geographies, v. 7, n. 1, p. 23-42, 2006.

BRASIL. Lei $N^{\circ}$ 10.233, de 5 de junho de 2001. Dispõe sobre a reestruturação dos transportes aquaviário e terrestre, cria o Conselho Nacional de Integração de Políticas de Transporte, a Agência Nacional de Transportes Terrestres, a Agência Nacional de Transportes Aquaviários e o Departamento Nacional de Infraestrutura de Transportes, e dá outras providências. Diário Oficial do União, Brasília, 2001. Disponível em:< http://www.planalto.gov.br/ccivil_03/LEIS/LEIS_2001/L10233.htm>. Acesso em: 28 out. 2020.

BRASIL. Ministério da Infraestrutura. Anuário Estatístico de Transportes 2010 a 2018. Brasília, 2019. Disponível em: <https://www.gov.br/infraestrutura/pt-br/ centrais-de-conteudo/suma-exec-aet-2010-2018-pdf>. Acesso em 29 ago. 2020.

CAZES, G. Tourisme et Tiers-Monde: Un Bilan Controverse. Paris: L'Harmattan, 1992.

CHRISTALLER, W. Some considerations of tourism location in europe: the peripheral regions underdeveloped countries-recreation areas. Papers in Regional Science, v. 12, n. 1, p. 95-105, 1964.

INSTITUTO BRASILEIRO DE GEOGRAFIA E ESTATÍSTICA (IBGE). Base

Cartográfica Contínua do Brasil, escala 1:250.000 - BC250: versão 2019. Rio de Janeiro, 2019. Disponível em: <http://geoftp.ibge.gov.br/cartas_e_mapas/bases_ cartograficas_continuas/bc250/> Acesso em: 29 ago. 2020. 
FUNDAÇÃO INSTITUTO DE PESQUISAS ECONÔMICAS (FIPE). Caracterização e dimensionamento do turismo doméstico no Brasil - 2010/2011. São Paulo, 2012. Disponível em: <http://www.dadosefatos.turismo.gov.br/dadosefatos/ demanda_turistica/domestica/> Acesso em: 28 out. 2020.

FRATUCCI, A. C. Os Lugares Turísticos: territórios do Fenômeno Turístico. GEOgraphia, Niterói, v.2, n.4, p.121-133, 2000.

FRATUCCI, A. C. Turismo e território: relações e complexidades. Caderno Virtual de Turismo, Rio de Janeiro, v. 14, n.1, 2014, p.87-96.

FRATUCCI, A.C.; MORAES, C.; ALLIS, T. Espaços e territórios do turismo: reflexões e indagações. In: SEMINÁRIO DA ASSOCIAÇÃO NACIONAL DE PESQUISA E PÓSGRADUAÇÃO EM TURISMO, Anais do Seminário da ANPTUR, 2015. Disponível em: <http://www.anptur.org.br/anptur/anais/v.11/DFP1_pdf/46.pdf>. Acesso em: 29 ago. 2020.

FORER, P. C.; PEARCE, D. G. Spatial Patterns of Package Tourism in New Zealand. New Zealand Geographer, v. 40, n. 1, p. 34-43, 1984.

HAESBAERT, R. O mito da desterritorialização: do fim dos territórios à multiterritorialidade. Rio de Janeiro: Bertrand Brasil, 2011.

KAFRUNI, S. Buser denuncia fiscalização da ANTT; órgão regulador fará apurações. Correio Braziliense, Brasília, 11 de janeiro de 2021. Disponível em: < https://www. correiobraziliense.com.br/economia/2021/01/4899653-buser-denuncia-fiscalizacaoda-antt-orgao-regulador-fara-apuracoes.html>. Acesso em: 12 mai. 2021.

KUNZ, J. As mobilidades turísticas como objeto de pesquisa: um panorama dos periódicos estrangeiros (2000-2014). Rosa dos Ventos - Turismo e Hospitalidade, v.7 n.3, p.377-391, 2015.

LÉVY, J. Os novos espaços da mobilidade. GEOgraphia, Niterói, v.3, n.6, p.7-17, 2001.

LÖFGREN, O. Storie delle Vacanze. Milano: Bruno Mondadori, 2006.

LUE, C. C.; CROMPTON, J.L.; FESENMAIER, D.R. Conceptualization of Multidestination Pleasure Trips. Annals of Tourism Research, v. 20, n.2, p. 289-30, 1993.

PALHARES, G. L.; FRAGA, C.; CASTRO, R. (Orgs.).Transportes e destinos turísticos: planejamento e gestão. Rio de Janeiro: Elsevier Campus, 2013. 
PEARCE, D. G. Spatial patterns of package tourism in Europe. Annals of Tourism Research, v. 14, n. 2, p. 183-201, 1987.

RAGAGNIN PIMENTEL, M.; PEREIRA, M.d.L. Tourism spatial distribution in Brazil: a recent assessment using thematic cartography. Journal of Hospitality and Tourism Insights, v. 4, n.2, p.318-334, 2021.

SOLHA, K. T.; BRAGA, D. C. O transporte rodoviário de fretamento eventual no estado de São Paulo e sua aproximação com a atividade turística: uma análise preliminar. Rosa dos Ventos - Turismo e Hospitalidade, Caxias do Sul, v. 8, n. 2, p.136-152, 2016.

SOLHA, K.T.; LUQUES, A. Transporte rodoviário de fretamento eventual: desafios e possibilidades para o turismo no Estado de São Paulo. (Relatório de Pesquisa). ECA/USPFRESP, São Paulo, 2011. Disponível em: <http://www.sinfrecar. org.br/portal/wpcontent/uploads/2010/06/FRESP_RELATORIO_SINTESE_VF.pdf>. Acesso em: 13 ago. 2020.

TAVARES, J. M.; LEITÃO, N. C. The determinants of international tourism demand for Brazil, Tourism Economics, v. 23, n. 4, p. 834-845, 2017.

TIDESWELL, C.; FAULKNER, B. Multidestination Travel Patterns of International Visitors to Queensland. Journal of Travel Research, v.34, n.4, p.364-374,1999.

UNWTO. Tourism Highlights 2018 Edition. UNWTO: Madrid, 2019.

WALTON, J. K. The origins of the modern package tour? British motor-coach tours in Europe, 1930-70 Journal of Transport History, v. 32, n. 2, p.145-163, 2011.

Recebido em: 20-10-2020.

Aprovado em: 21-08-2021. 
$S$ 